\title{
Canadians face unappealing medicare options, ex-Bank of Canada governor says
}

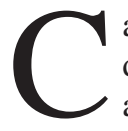

anada's health care "spending disease" will become unmanageable over the next two decades unless Canadians embrace such unappealing cures as reducing medical services covered by public health care, allowing a private health system to develop or dipping deeper into their pockets, whether through taxes or copayments, according to a new report from a former Bank of Canada governor.

By 2031, the annual health expenditure on the average Canadian will be about $\$ 10700$, compared to $\$ 4900$ in 2009, states the report, written by David Dodge, who also served stints as the deputy minister of the federal departments of finance and health, and economist Richard Dion, a senior business advisor at Bennett Jones LLP, on behalf of the C.D. Howe Institute in Toronto, Ontario.

Funding the rising costs of health care will be difficult, requiring "some combination" of four actions: reducing government-funded public services not related to health; increasing taxes; delisting services from medicare or making patients co-pay for more services; and degrading publicly funded health care standards while developing a privatelyfunded system to provide "better-quality care for those willing to pay for it."

"None of these options is appealing; there is no easy way to manage the chronic healthcare spending rise," states the report, Chronic Healthcare Spending Disease: A Macro Diagnosis and Prognosis (www.cdhowe.org/pdf /Commentary_327.pdf). "In this paper we have attempted to provide a diagnostic of the spending disease and a prognosis of its evolution. The prognosis is not good, even if we are incredibly successful in improving the efficiency and effectiveness of healthcare delivery."

Dodge and Dion added that the time has come for Canadians to have an

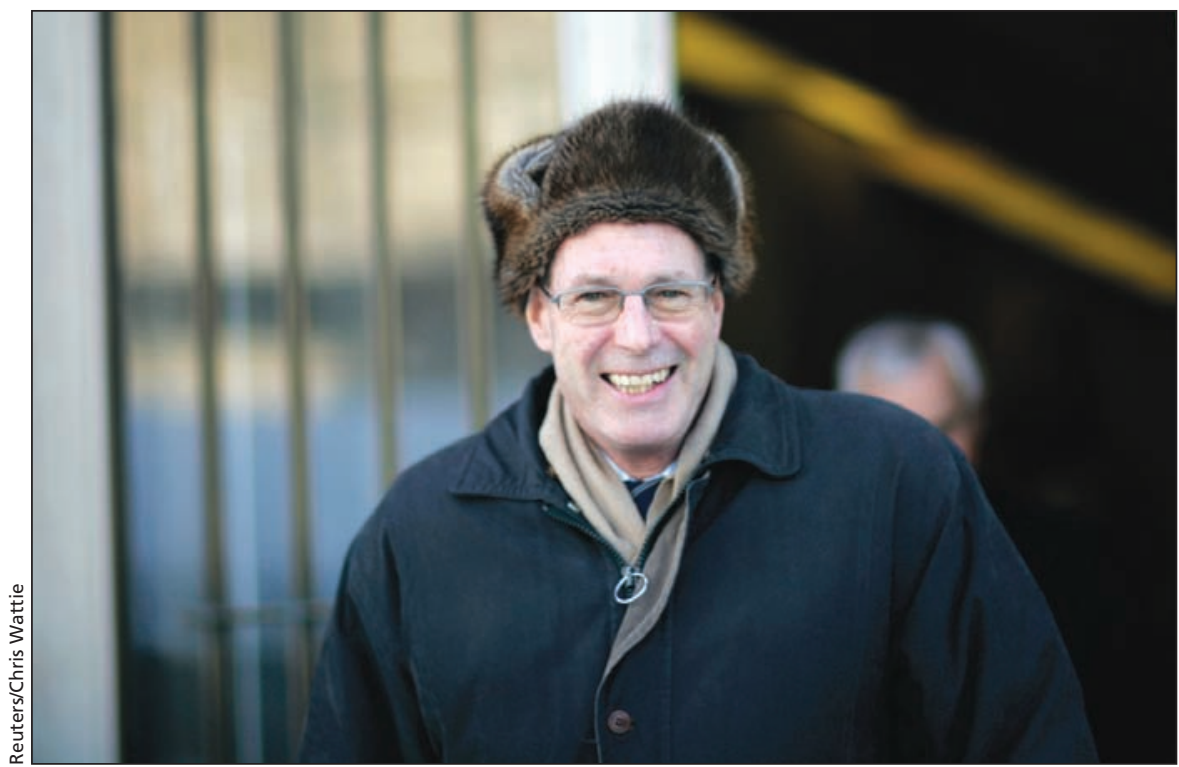

Former Bank of Canada governor David Dodge and colleagues at the C.D. Howe Institute in Toronto, Ontario, say that the time has come for Canadians to have an "adult discussion" about the sustainability of their health care system.

"adult discussion" on the sustainability of the health care system.

Based on historical experience, the percentage of national income devoted to health care may reach $19 \%$ by 2031 . Even in an optimistic scenario, which assumes cost savings through increases in the health system's efficiency and effectiveness, that figure may be $15 \%$. In 2009, by contrast, Canada spent $12 \%$ of its gross domestic product (GDP) on health care.

Will Canada's GDP also increase over the next 20 years? It will, actually, but the rate of its growth will shrink. According to the report, nominal (not counting inflation) GDP growth will decelerate from $5.25 \%$ for 2009-2012 to $3.75 \%$ for $2021-2031$. This is attributed to a loss of productivity as aging Canadians leave the work force. In an optimistic case - which assumes two things: new government policies will increase the rate of people aged 55-plus in the workforce; and Canada's private sector will "catch up" with the more productive United States economy - the nominal GDP growth may still fall to $4.5 \%$ by $2021-2031$.

Meanwhile, the annual growth of health care expenditures from 2012 to 2031 may be as high as $6.4 \%$. This increase is driven by several factors, including an aging population, changes in technology and the rising prices of health care services, which are essentially driven by "the evolution of wage and salaries in the healthcare sector and drug prices."

Under the "business-as-usual" scenario, states the report, aging and technology will each account for almost half of yearly growth in the health care spending-to-GDP ratio.

"From a policy perspective, one important outcome of these projections is the very important role played by technology in driving the healthcareto-GDP ratio," the report states. "This makes it a key area for health-policy initiatives aimed at improving the efficiency of the delivery system and the incentives for most cost-effective healthcare intervention, in contrast with aging, which is equally important 
but will be little influenced by healthyliving and healthcare policies over the next 20 years."

Even under optimistic scenarios, Canadians should expect to start paying more for private insurance, long-term care and out-of-pocket fees for health services, states the report. And governments, which currently fund about $70 \%$ of all health care expenditures, will have to somehow increase their revenues. That could mean higher taxes or a smaller medicare basket.

"Even if we in Canada are incredibly successful in improving the productivity, efficiency and effectiveness of the healthcare system - our optimistic case - we face difficult but necessary choices as to how we finance the rising costs of healthcare and manage the rising share of additional income devoted to it," the report concludes.

Dr. Danielle Martin, chair of Canadian Doctors for Medicare, agrees with the report's findings on the rising costs of health care. The authors' methodology is sound, she says, and they are asking some of the right questions.

"Having said that, the paper tells exactly half the story," she adds. "It omits a huge area that I think is vital for people to understand to have a conversation about these issues. While it's true that health care spending as a portion of GDP is increasing and will continue to increase, the portion of spend- ing on health care that is public has been remarkably stable for decades."

The major drivers of health care spending in Canada are things not covered by medicare, such as the cost of pharmaceuticals, which gets little mention in the report, says Martin. "It's not just an omission. It's a glaring omission."

The best means of reducing costs in health care are to move more services into the medicare basket, not remove them, as the report suggests, says Martin. In a central, single-payer system, prices can be kept down through regulations and bulk buying. For health care provided by private companies, it is far harder to decrease costs.

"By far, the best strategy for controlling costs is to pay for more things publicly," says Martin. "You will get the best bang for your buck in a singlepayer system."

This strategy should include something else not mentioned in the report: the creation of a pharmacare system, says Dr. Irfan Dhalla, scientist at the Keenan Research Centre of the Li Ka Shing Knowledge Institute of St. Michael's Hospital in Toronto, Ontario.

"Dodge and Dion quite clearly say that increased spending on healthcare will not 'eat up' all or even the majority of our gains in income. That's the good news. But we should not settle for mere sustainability," Dhalla writes in an email. "Everyone agrees that we need to improve both the quality and the efficiency of our health care system. Unfortunately, the federal government has provided zero leadership on these issues - consider for example the lack of movement on a national pharmacare program, which would likely reduce total healthcare spending substantially. I believe that Canadians would be willing to consider a small, dedicated tax to pay for such a program, so long as they believed that it would be run efficiently and not subject to influence from the pharmaceutical industry."

It is also important to note whenever a story surfaces about a looming Canadian health care crisis that health care costs are eating away at the GDP in all industrialized countries, says Dr. Gordon Guyatt, a professor in the department of clinical epidemiology and biostatistics at McMaster University in Hamilton, Ontario.

But the fact is that Canada is doing remarkably better than most countries in this area, particularly in stabilizing the cost of delivering publicly funded health care, Guyatt adds. "Because we are spending more on private care, the portion of the GDP spent on public health expenditure is almost exactly what is was 20 years ago." - Roger Collier, CMAJ

CMAJ 2011. DOI:10.1503/cmaj.109-3858 